\title{
The need for more reliable information on the incidence and prevalence of occupationally related problems
}

\author{
M.-A. Boillat and B. Noël \\ Institute of Occupational Health Sciences, University of Lausanne, \\ Switzerland
}

The need for reliable information regarding the incidence and prevalence of occupational diseases is obvious to public health officials who have to allocate scarce resources to the investigation and prevention of such diseases. Many data sources on occupational diseases are available. They include workers' compensation systems, hospital discharge records, cancer and death registries, etc. Unfortunately, all these sources have their own limits and consequently reliable data are often unavailable'. Even diseases with a well-known association with work, such as pleural mesothelioma or sinonasal adenocarcinoma, are often not reported. Skov et $a .^{2}$ estimate that under-reporting of these two occupational cancers is close to $50 \%$. Considerable under-reporting has also been noticed in Switzerland for carpal tunnel syndrome ${ }^{3}$. Late recognition of occupational diseases may have medical as well as economic consequences. For instance, early diagnosis of an isocyanate asthma case might cost the Swiss National Insurance Company approximately 19000 Swiss francs, while late diagnosis costs about 211000 Swiss francs 4 .

In Switzerland, about 5400 occupational disease cases are compensated each year ${ }^{5}$. There were only 58 certified occupational physicians in the country in 1992, which means that most cases are diagnosed in a regular medical practice. Nevertheless, many physicians are probably not adequately trained to recognize work as a cause of illness 1 .

Both clinical and workplace information with reliable exposure evaluation are critical in the recognition and management of occupational disease. Occupational health centres with their clinical and industrial hygiene services are a unique resource for detecting adverse health effects secondary to occupational exposures ${ }^{6}$. For instance, in a retrospective study among 298 patients examined at the outpatient clinic of the Institute of Occupational Health Sciences of the University of Lausanne, it was interesting to observe that the spectrum of disease is quite different to that usually observed for workers' compensation systems.

Correspondence and reprint requests to: Dr M.-A. Bolllat, Associate Professor, IUMHT, Bugnon 19, CH-1005 Lausanne, Switzerland.
Approximately half of these patients have health problems directly due to their occupation. However, instead of the usual general prevalence of musculoskeletal or stress-related disorders, the cases were mainly represented by respiratory diseases ( $41 \%$ ) and intoxications $(31 \%)$, in which solvents are often involved.

This discrepancy can be explained by the fact that simple conditions such as contact dermatitis or tendonitis are more easily recognized by insurance companies as work-related. Conditions such as occupational asthma or chronic solvent intoxication may go unrecognized. In contrast, complex conditions are more often seen in occupational health clinics and may be over-represented. Despite these referral biases, and with the exception of asbestos-related problems which are not very frequent in Switzerland, the results previously mentioned are similar to those of Cullen and Cherniack in Connecticut ${ }^{7}$.

In some European countries, an increasing number of workers are currently receiving compensation benefits for chronic solvent neurotoxicity, although specific and objective clinical data are often not available. In Switzerland, only 65 cases of acute and chronic solvent intoxication were recognized in 1989 by the Swiss National Insurance Company (about $1 \%$ of all compensated occupational diseases) ${ }^{5}$. In our retrospective study, most cases of suspected chronic solvent intoxication remained unresolved due to insufficient objective and specific clinical data. Only six cases were recognized as solvent-related with a sufficient probability. One example of insufficient objective data is the lack of determination of urinary dimethylbenzoic acid in workers exposed to white spirit ${ }^{8}$, despite the wide use of this solvent by painters and related workers. These results confirm that chronic solvent neurotoxicity is particularly difficult to demonstrate on an individual basis and that it remains one of the most difficult diagnoses for occupational physicians.

If preventive measures are only based on data obtained from compensated occupational disease, this does not take into account the numerous situations where the ailment is only partially related to work ${ }^{9}$. This is particularly true for diseases such as depressive states and back problems. For instance, in 1989, only five cases of back problems were compensated as 
occupational disease in Switzerland out of a workforce of approximately two million. Compared to the prevalence of these problems in daily life, we do not need much statistical analysis to conclude that they are underreported.

The main objective of occupational medicine is the prevention of work-related problems, which cannot be achieved by simple analysis of compensated diseases. A better estimation of the reality needs a prospective approach, particularly:

- promotion of risk analysis and management, in cooperation with industrial hygienists

- an increase in the training of physicians in the recognition of work as a cause of illness or ailment

- establishment of epidemiological surveillance and clinical studies to provide detailed exposure data, particularly in the recognition of new environmental hazards

- assessment of occupational risk on an individual basis, in order to consider inter-individual variation.

The difficulties encountered in the recognition of many occupational diseases (particularly due to long latency and the lack of objective diagnostic criteria) imply a need for multiple data sources.

\section{REFERENCES}

1. Landrigan PJ, Baker B. The recognition and control of occupational discase. JAMA 1991; 266: 676-80.

2. Skov T, Mikkelsen S, Svane O, Skov BG, Lynge E. Identifying occupational cancer. Am $\mathcal{F}$ Ind Med 1992; 21: 281-5.

3. Delgrosso I, Boillat MA. Carpal tunnel syndrome: the role of occupation. Int Arch Occup Environ Health 1991; 63: 267-70.

4. Waldburger $R$, Hofmann $M$, Rüegger $M$, Knoblauch $A$. Peak-flow-Profil und Gutachten. Schweiz Med Wochenschr 1992; 122: 1070-8.

5. Statistique des maladies professionnelles de la CNA. Situation actuelle et tendances. Lucerne: Caisse nationale suisse d'assurance en cas d'accidents, 1992.

6. Welch $\mathrm{L}$. The role of occupational health clinics in surveillance of occupational disease. Am 9 Public Health 1989; 79: 58-60.

7. Cullen MR, Cherniack MG. Spectrum of occupational disease in an academic hospital-based referral center in Connecticut from 1979 to 1987. Arch Intern Med 1989; 149: $1621-6$.

8. Pfaffli P, Harkonen H, Savolainen H. Urinary dimethylbenzoic acid excretion as an indicator of occupational exposure to white spirit. $\mathcal{F}$ Chromatogr 1985; 337: 146-50.

9. Gennart JP, Hoet $P$, Lison $D$, Lauwerys $R$, Coche $E$, Lambert $M$. The importance of accurate employment histories of patients admitted to units of internal medicine. Scand $\mathcal{F}$ Work Environ Health 1991; 17: 386-91.

\title{
Occupational
} MEDICINE

\section{Volume 43 Supplement Number 11993}

\author{
Selection of papers from the International Workshop on Health Services \\ Research in Occupational Health (Amsterdam) \\ 22-24 October 1992
}

This supplement to Occupational Medicine marks the start of a new scientific committee of the International Commission of Occupational Health the Scientific Committee on Health Services Research and Evaluation in Occupational Health. It comprises a selection of papers presented and discussed during a workshop held on this theme in Amsterdam in October 1992. This workshop was organized primarily by the TNO Institute for Preventive Medicine and the Department of Social Medicine at the Vrije Universiteit in Amsterdam.

A limited number of copies of this supplement are still available at the price of $£ 23.40$ (UK/Europe) and $£ 25.50$ (Rest of the World).

Orders can be placed by contacting the following directly:

Turpin Distribution Services Ltd., Blackhorse Road, Letchworth, Herts SG6 IHN, UK.

Tel: +44462672555 or Fax: +44462480947 . 